\title{
Serum lipids four weeks after acute myocardial infarction are a valid basis for lipid lowering intervention in patients receiving thrombolysis
}

\author{
Roland Carlsson, Gunnar Lindberg, Lars Westin, Bo Israelsson
}

Section of Cardiology, Department of Medicine, Central

Hospital, Karlstad,

Sweden

R Carlsson

Centre for Public

Health Research,

Karlstad, Sweden

G Lindberg

Department of

Cardiology, Lund

University, Malmö,

Sweden

L Westin

B Israelsson

Correspondence to:

Dr R Carlsson, Section of Cardiology, Department of Medicine, Central Hospital S-651 85 Karlstad, Sweden.

Accepted for publication

15 February 1995

\begin{abstract}
Objective-To compare serum concentrations of total cholesterol, low density lipoprotein (LDL) cholesterol, high density lipoprotein (HDL) cholesterol, and triglycerides four weeks after acute myocardial infarction with baseline levels measured within 24 hours after onset of symptoms.

Design-A prospective study including 141 patients with acute myocardial infarction who were admitted to the coronary care unit at a general hospital.

Measurements-Fasting serum concentrations of total cholesterol, LDL cholesterol, HDL cholesterol, and triglycerides. Main results-In patients receiving thrombolytic therapy, no significant differences were found in serum lipids four weeks after admission compared to values estimated within $\mathbf{2 4}$ hours from onset of symptoms. In patients not receiving thrombolytic therapy, total cholesterol and low density lipoprotein cholesterol showed a minor increase four weeks after admission compared to values obtained within 24 hours after onset of symptoms. High density lipoprotein cholesterol and triglycerides remained unchanged. Conclusions-In patients with acute myocardial infarction receiving thrombolytic therapy, serum lipids measured four weeks after onset of infarction are reasonably valid estimates of baseline
\end{abstract}

lipid levels and may be used to decide about lipid lowering interventions. This information can be a basis for actions against hyperlipidaemia early after hospital discharge when the patient is highly motivated to change lifestyles and is still in close contact with a cardiologist or other physician.

(Br Heart f 1995;74:18-20)

Keywords: serum lipids; myocardial infarction; thrombolysis

Acute myocardial infarction is associated with metabolic and hormonal disturbances. The serum lipid concentrations are usually not assessed immediately after myocardial infarction because the values undergo changes during the acute phase reaction. ${ }^{14}$ Several studies have shown significant decreases in serum total cholesterol, high density lipoprotein (HDL) cholesterol, and low density lipoprotein (LDL) cholesterol, and an increase in triglycerides during the days immediately after infarction in patients not receiving thrombolytic therapy. The lipid concentrations return to their initial levels after several months..$^{5-9}$ The acute phase reaction is less pronounced in patients receiving thrombolysis. ${ }^{10}$ However, on day 1 after acute myocardial infarction, lipid concentrations are reported not to be influenced ${ }^{112}$ or to be influenced only to a limited degree ${ }^{13}$ by acute phase reaction. ${ }^{14}$ Thus during this period lipid levels are reasonably valid estimates of baseline levels.

It is advantageous if interventions against raised serum lipids can be initiated during the time in the hospital or immediately after discharge, when patients are highly motivated to change their lifestyles and are still in close contact with the cardiologist or general physician. Unfortunately, for many patients the prevention programme is delayed because of the practice of not screening serum lipids until 3-6 months after hospital discharge. Thus, if baseline values can be reliably assessed at four weeks after an infarct, this might contribute to a successful intervention against raised serum lipids.

The aim of this study was to compare serum total cholesterol, LDL cholesterol, HDL cholesterol, and triglycerides four weeks after acute myocardial infarction with baseline values measured within 24 hours after onset of symptoms in patients receiving or not receiving thrombolytic therapy. 
Table 2 Age, gender, and number of patients receiving and not receiving thrombolysis

\begin{tabular}{lcll}
\hline & No & Mean (SD) & Range \\
\hline Men receiving thrombolysis & 55 & $58 \cdot 5(8 \cdot 3)$ & $43-79$ \\
Women receiving thrombolysis & 20 & $63 \cdot 3(6 \cdot 4)$ & $42-69$ \\
& 57 & $59 \cdot 9(6 \cdot 6)$ & $45-76$ \\
Men not receiving thrombolysis & 9 & $64 \cdot 2(5 \cdot 5)$ & $53-69$ \\
\hline
\end{tabular}

Methods

This study includes 141 consecutive patients with acute myocardial infarction admitted to the coronary care unit at Malmö General Hospital, Sweden, between October 231989 and April 30 1992, and who had serum lipids estimated at admission and four weeks later. They were not on lipid lowering drugs. The diagnosis of myocardial infarction was established on the basis of an increase in serum creatinine kinase and its MB subunits, chest pain, and electrocardiographic changes. If not contraindicated, a $\beta$ blocker was given to reduce the risk of reinfarction. Thrombolysis (as streptokinase infusion, $1500000 \mathrm{U}$ in $1 \mathrm{~h}$ ) was given if the patient had had infarction pain for less than 10 hours and an ST segment elevation of $2 \mathrm{~mm}$ or more in at least two precordial leads, or more than $1 \mathrm{~mm}$ in the standard leads. ${ }^{1516}$

After discharge from hospital all patients attended a secondary prevention programme. During the first and third weeks after discharge, the patients visited a special coronary nurse for dietary advice and risk profile information. No patient was treated with lipid lowering drugs during the first four weeks of follow up. Basic characteristics of all the patients at entry are given in table 1.

Blood samples were collected by venepuncture from overnight fasting patients between 0800 and $0900 \mathrm{~h}$ on the day after admission to the coronary care unit and again four weeks later. Serum total cholesterol, HDL cholesterol, and triglycerides were measured by enzymatic assays (Technicon DAX 48, Bayer). LDL cholesterol was calculated according to Friedewald's formula.

Table 3 Serum lipid concentrations within 24 hours after onset of symptoms and four weeks after admission in 66 patients who received thrombolysis and in 75 patients who did not receive thrombolysis

\begin{tabular}{|c|c|c|c|c|}
\hline & \multirow{2}{*}{$\begin{array}{l}\text { Test value } \\
\text { (mmolll) } \\
\text { within } 24 \text { hours } \\
\text { after onset } \\
\text { of symptoms } \\
\text { (mean (SD)) }\end{array}$} & \multirow{2}{*}{$\begin{array}{l}\text { Test value } \\
\text { (mmolll) } \\
\text { four weeks } \\
\text { after admission } \\
\text { (mean }(S D))\end{array}$} & \multicolumn{2}{|c|}{ Paired differences (mmol/l) } \\
\hline & & & Mean & $\begin{array}{l}\text { (95\% confidence } \\
\text { interval) }\end{array}$ \\
\hline \multicolumn{5}{|c|}{ Patients not receiving thrombolysis } \\
\hline Total cholesterol & $5.68(0.93)$ & $5.98(0.96)$ & $0 \cdot 294$ & $(0.072,0.517)$ \\
\hline LDL cholesterol & $3.94(0.89)$ & $4 \cdot 24(0 \cdot 87)$ & $0 \cdot 291$ & $(0.079,0.502)$ \\
\hline HDL cholesterol & $1.07(0.28)$ & $1 \cdot 10(0 \cdot 30)$ & 0.029 & $(-0.020,0.079)$ \\
\hline Triglyceride & $1.43(0.56)$ & $1.48(0.56)$ & 0.052 & $(-0.056,0.160)$ \\
\hline \multicolumn{5}{|c|}{ Patients receiving thrombolysis } \\
\hline Total cholesterol & $5.97(1 \cdot 10)$ & $5.92(0.96)$ & -0.052 & $(-0.251,0 \cdot 148)$ \\
\hline LDL cholesterol & $4 \cdot 16(1 \cdot 06)$ & $4 \cdot 20(0.82)$ & 0.038 & $(-0.153,0.228)$ \\
\hline HDL cholesterol & $1 \cdot 07(0 \cdot 25)$ & $1.03(0.24)$ & -0.041 & $(-0.086,0.005)$ \\
\hline Triglyceride & $1.60(0.68)$ & $1.60(0.60)$ & 0.001 & $(-0.143,0.144)$ \\
\hline
\end{tabular}

LDL, low density lipoprotein; HDL, high density lipoprotein

\section{STATISTICAL METHODS}

A two sampled Student's $t$ test was used to determine the significance of the differences in mean changes. A logistic regression model was used to compare differences in lipid concentrations with adjustment for age and gender. Serum triglyceride concentrations were entered after logarithmic transformation. Differences were considered significant at $\mathrm{P}<$ $0 \cdot 05$. All tests were two tailed.

\section{Results}

In total 141 patients with acute myocardial infarction, 112 men, mean age (SD) $59 \cdot 2$ $(7 \cdot 5)$ years, and 29 women, mean age (SD) $63.6(6.0)$ years, were included in the study. Fifty five men (49\%) and 20 women $(69 \%)$ received thrombolysis (table 2 ).

Lipid values estimated on the first occasion (within 24 hours after onset of symptoms) in patients receiving thrombolysis were not significantly different from those in patients not receiving thrombolysis. Nor were there any significant differences between the two groups in lipid concentrations estimated four weeks after admission (table 3).

As further seen in table 3 , in patients not receiving thrombolysis, the mean serum cholesterol concentration at follow up four weeks after admission was $0.29 \mathrm{mmol} / \mathrm{l}$ above the concentration measured within 24 hours after onset of symptoms. The difference was statistically significant $(P=0.01)$. The mean LDL cholesterol at follow up was also above the concentration measured within 24 hours after onset of symptoms. The difference was the same as for total cholesterol, $0.29 \mathrm{mmol} / 1$ $(P=0.01)$. The changes in HDL cholesterol and triglyceride concentrations were not statistically significant. In patients receiving thrombolysis, no significant differences were seen in serum lipids four weeks after admission compared to the values obtained within 24 hours after the onset of symptoms.

The changes in lipid concentrations were compared in patients who did or did not receive thrombolysis in a multivariate logistic regression model including age and gender as covariates. The increase in total serum cholesterol between the first estimation and the second estimation four weeks later in patients not receiving thrombolysis was significantly different from the decrease in patients receiving thrombolysis $(P=0.035)$. The increase in the HDL cholesterol in patients not receiving thrombolysis was also significantly different from the decrease in patients receiving thrombolysis $(P=0.016)$. The changes in LDL cholesterol and triglycerides did not differ significantly between the two groups.

\section{Discussion}

In 66 patients with acute myocardial infarction not treated with streptokinase, our results show a minor but statistically significant increase in the levels of total cholesterol and LDL cholesterol four weeks after admission to hospital compared to values obtained within 
24 hours after the onset of symptoms. Both mean differences were $0.3 \mathrm{mmol} / \mathrm{l}$ and thus were of limited clinical significance. There were no significant changes in lipid levels in 75 patients receiving thrombolytic therapy.

For ethics reasons, patients were not randomly selected to receive thrombolytic therapy. Consequently, the differences between the two groups may be caused by some confounding variable not controlled for in this study, for example, patients not receiving thrombolytic therapy did not have to fulfil the less than 10 hours pain criterion on admission to hospital. The first serum samples obtained in those patients might have been collected somewhat later after the onset of symptoms compared to patients given thrombolytic therapy, and may thus have been affected by the early acute phase reaction lowering cholesterol in the first serum sample. Indeed, patients not receiving thrombolytic therapy had lower initial LDL cholesterol and total cholesterol values (table 3), though this did not achieve significance. Furthermore, thrombolysis has been shown to depress the acute phase reaction ${ }^{10}$ and might therefore be an additional explanation for the higher LDL cholesterol and total cholesterol values measured within 24 hours from onset of symptoms in patients receiving streptokinase.

Major cardiac drugs including $\beta$ blockers, frusemide, and other diuretic drugs may affect lipid concentrations. In our study, patients were treated with a $\beta$ blocker after myocardial infarction. However, metabolic changes resulting from these agents are not expected to occur for at least four weeks. ${ }^{1718}$ Thus it is unlikely that $\beta$ blocking agents introduced during follow up affected our results.

When patients receiving and not receiving thrombolysis were compared, only the changes in HDL cholesterol values were significantly different. This might indicate an acute phase reaction at the four week follow up in patients receiving thrombolysis. However, this supposition is not supported by changes in LDL and total cholesterol and is thus of limited significance.

In conclusion, in patients receiving thrombolysis, serum lipids measured four weeks after acute myocardial infarction are reasonably valid estimates of baseline lipid values and may be used to decide about lipid lowering interventions. This is of importance if lipid levels were not estimated within 24 hours from the onset of symptoms, since this information can be a basis for intervention against hyperlipidaemia early after hospital discharge when patients are highly motivated to change their lifestyles and are still in contact with a cardiologist or general physician.

We thank Mrs Carin Alm RN and Mrs Elisabeth Hansson RN $\frac{T}{D}$ for their excellent service, and Dr Ronnie Willenheimer and Dr Charles Cline. This study was supported by grants from the Swedish Heart Lung Foundation, the Harald Lundströms Foundation, and the Merck Sharp and Dohme Foundation.

1 Fyfe T, Baxter RH, Cochran KM, Booth EM. Plasma lipid changes after myocardial infarction. Lancet 1971;ii: 997-1001.

2 Ryder R, Hayes T, Mulligan I, Kingswood J, Williams S, Owens D. How soon after myocardial infarction should $\varrho$ plasma lipid values be assessed? $B M 7$ 1984;289:1651-3. क

3 Gore J, Goldberg R, Matsumoto A, Castelli W, McNamara P, Dalen J. Validity of serum total cholesterol level obtained within 24 hours of acute myocardial $\rightarrow$

infarction. Am $\mathcal{F}$ Cardiol 1984;54:722-5.

Jackson R, Scragg R, Marshall R, White H, O'Brien KK, Small C. Changes in serum lipid concentration during first 24 hours after myocardial infarction. $B M \mathcal{F} 1987$; 294:1588-9.

5 Avogaro P, Bittolo Bon G, Cazzolato G, Quinci G, $\stackrel{7}{\perp}$ Caturelli $G$. Variations in apolipoproteins $B$ and A during the course of myocardial infarction. Eur $\mathcal{f}$ Clin Invest $\vec{\infty}$ 1978;8:121-9.

6 Enger S, Ritland S. Serum lipoprotein pattern in myocardial 음 infarction. Acta Med Scand 1970;187:365-71.

7 Mundy GR, McPherson DG. Variations in serum choles- terol levels after myocardial infarction. Med $\mathcal{f}$ Aust 1973 ; 1:278-83.

8 Ritland S, Blomhoff J, Enger S, Skrede S, Gjone E. The esterification of cholesterol in plasma after acute $\vec{c}$ myocardial infarction. Scand $\mathcal{f}$ Clin Lab Invest 1975; of 35:181-7.

9 Tibblin G, Cramér K. Serum lipids during the course of an acute myocardial infarction and one year afterwards. Acta Med Scand 1963;174:451-7.

10 Pietilä K, Harmoinen A, Teppo A-M. Acute phase reac- $\bar{\partial}$ tion, infarct size and in-hospital morbidity in myocardial infarction patients treated with streptokinase or recominfarction patients treated with streptokinase or recombinant tiss

11 Sewdaresen $M$, Vythilingum S, Jialal I, Nadar R. Plasma $\overline{\bar{O}}$ lipids can be reliably assessed within 24 hours after acute 3

12 Ahnve S, Angelin B, Edhag O, Berglund L. Early determination of serum lipids and apoproteins in acute myocardial infarction: possibly for immediate intervention. f Intern Med 1989;226:297-301.

13 Ballantyne F, Melville D, Mckenna J, Morrison B, ֻ Ballantyne D. Response of plasma lipoproteins and acute phase proteins to myocardial infarction. Clin Chim Acta 1979;99:85-92.

14 Rosenson R. Myocardial injury: the acute phase response and lipoprotein metabolism. I Am Coll Cardiol 1993;22:

15 Yusuf S, Collins R, Peto R, Furberg C, Stampfer M, 은 Goldhaber $\mathrm{S}$, et al. Intravenous and intracoronary fibrinolytic therapy in acute myocardial infarction: overview of results on mortality, reinfarction and side effects from 33 randomized trials. Eur Heart $\mathcal{f} 1985 ; 6: 556-85$.

16 Gruppo Italiano per lo Studio Della streptochinasi Nell N Infarctio Miocardico (GISSI). Effectiveness of intravenous thrombolytic treatment in acute myocardial $N$ infarction. Lancet 1986;i:397-402.

17 Rosenson RS. The truth about beta-blocker adverse $\omega$ effects. F Ambulatory Monitoring 1993;6:998-1000.

18 Wolinsky $H$. The effects of beta-adrenergic blocking agents on blood lipid levels. Clin Cardiol 1987;10:561-6. 